\title{
Characteristics of Heat Transfer over the Ice Covered Sea of Okhotsk during Cold-air Outbreaks
}

\author{
Jun INOUE \\ Institute of Low Temperature Science, Hokkaido University, Sapporo, Japan \\ Jun ONO \\ Graduate School of Environment Earth Science, Hokkaido University, Sapporo, Japan \\ Yoshihiro TACHIBANA \\ IARC, Frontier Research System for Global Change, Yokohama, Japan \\ Liberal Arts Education Center, Tokai University, Hiratsuka, Japan \\ Meiji HONDA \\ Institute for Global Change Research, Frontier Research System for Global Change, Yokohama, Japan \\ Katsushi IWAMOTO ${ }^{1}$ \\ Graduate School of Environment Earth Science, Hokkaido University, Sapporo, Japan \\ Yasushi FUJIYOSHI and Kensuke TAKEUCHI ${ }^{2}$ \\ Institute of Low Temperature Science, Hokkaido University, Sapporo, Japan \\ (Manuscript received 17 September 2001, in revised form 13 June 2003)
}

\begin{abstract}
Heat transfer coefficients, and relative importance of factors affecting surface turbulent heat flux in sea-ice covered ocean, were investigated using data obtained by rawinsonde observations over, and around, the southwestern region of the Sea of Okhotsk from Jan. to Feb. in 1998, 1999 and 2000. The range of the fluxes estimated by an atmospheric heat budget analysis was large, associated with the ice concentration and synoptic situation. The turbulent heat fluxes from the open water surrounded by the sea ice are always positive (upward). However, the heat flux through sea-ice surface tends to be negative
\end{abstract}

Corresponding author and Present affiliation:

Jun Inoue, Georgia Institute of Technology, Atlanta, GA, USA.

E-mail: inoue@lowtem.hokudai.ac.jp

1 Present affiliation: National Research Institute for Earth Science and Disaster Prevention, Nagaoka, Japan.

2 Present affiliation: Frontier Observation Research System for Global Change, Yokosuka, Japan.

(C) 2003, Meteorological Society of Japan 
(downward) over sea-ice area associated with the relationship between the air and ice-surface temperature. Using the obtained turbulent heat fluxes and a bulk formula, relationships of turbulent heat fluxes with ice concentrations and atmospheric parameters were investigated, and a representative value of the bulk heat transfer coefficient was obtained. The estimated conditional bulk heat transfer coefficient $\left(1.33 \times 10^{-3}\right)$ in the Sea of Okhotsk shows a smaller value than that in the Arctic region, reflecting the difference of the ice conditions, and thermal conditions in the boundary layer. Through an idea of the insulating coefficient, which measures degrees of the insulating effect of sea ice on the heat transfer, we explained that the sea ice works as a more effective insulator in weaker cold-air outbreaks. From a regression analysis, we found that the primary contribution to the amount of turbulent heat flux is the ice concentration, and second is the air temperature in the boundary layer.

\section{Introduction}

When cold-air masses break out from Siberia in winter, they are modified over relatively warm sea surface. As a result of heat and moisture supply from the ocean to atmosphere, cloud streets are formed over the Sea of Japan and the Sea of Okhotsk as exemplified by a satellite imagery in Fig. 1. However, when the sea ice exists (e.g., the Sea of Okhotsk), the heat exchange between air and sea surface is suppressed over the sea ice, because it works as an insulating material.

So far, it has been pointed out that the large fluctuations in the sea-ice coverage of the marginal ice zone are mainly associated with the large-scale atmospheric circulation (e.g., Arctic regions: Walsh and Johnson 1979; the Bering Sea: Overland and Pease 1982; the Baltic Sea: Omstedt and Chen 2001; the Sea of Okhotsk: Cavalieri and Parkinson 1987). On the other hand, some numerical studies pointed out that the sea ice in the Sea of Okhotsk possibly influences the atmospheric circulation through dynamic and thermodynamic processes locally, and globally (e.g., Okubo and Mannoji 1994; Honda et al. 1999). Therefore, in order to evaluate the effect of sea ice on the climate system, the quantitative estimate of the turbulent heat fluxes and heat budget are indispensable.

In the Arctic Ocean, however, there are a number of observations and numerical studies in terms of the turbulent heat fluxes over leads and polynyas. One of the most prominent efforts is determination and parametarization of the heat transfer coefficients which usually depend on atmospheric stability and fetch-width of leads and polynyas (e.g., Deardorff 1968; Andreas and Murphy 1986). Considering typical difference in the air-sea temperature difference and ice conditions between the Arctic region and the Sea of Okhotsk, it is not appropriate to apply these Arctic values directly to the latter. In this respect, it is important to understand heat transfer characteristics in the Sea of Okhotsk and properly estimate turbulent heat fluxes supplied to the atmosphere there.

Recently, using a one-dimensional thermodynamic model, Toyota et al. (2000) estimated mean turbulent heat fluxes, and heat budget, in the southwestern region of the Sea of Okhotsk during observational periods based on in-situ meteorological and sea-ice thickness data obtained through an icebreaker expedition. Iwamoto et al. (2001) also estimated the turbulent heat fluxes over the Sea of Okhotsk using radiosonde data. They found that the turbulent heat fluxes depend on the mixed layer height, which reflects the insulating effect of sea ice on heat transfer between the ocean and atmosphere. Not only using the upper air sounding data, but also using the maritime meteorological and sea-ice thickness data, Inoue et al. (2001) estimated the mean turbulent heat fluxes under cold-air outbreaks. Although the turbulent heat fluxes are smaller than $100 \mathrm{~W} \mathrm{~m}^{-2}$, they noted that the amount is not negligible on the surface heat balances. However, they did not consider the heat fluxes over open water and sea ice separately.

The major purpose of this study is to propose heat transfer coefficients over the ice-covered Sea of Okhotsk and to determine relative importance of factors affecting surface turbulent heat fluxes. For this purpose, in every January and February from 1998 to 2000, the radiosonde observations are carried out in the southern region of the Sea of Okhotsk. First, the turbulent heat fluxes are calculated by an atmospheric heat budget analysis. Next, a bulk model is constructed, and then examine the relationship between the turbulent heat flux and 


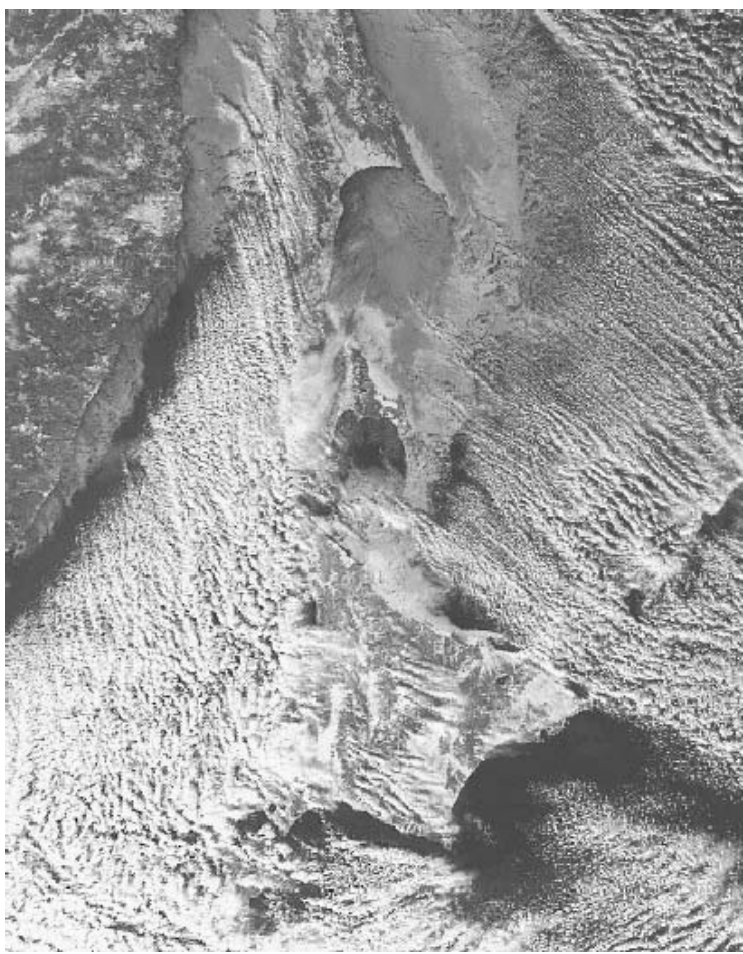

Fig. 1. NOAA-14 satellite imagery of channel 2 on 0457 UTC 26 Jan. 2000.

ice cover or meteorological conditions through a multivariate regression analysis, and compare the characteristics of the heat transfer with those of polar regions.

This paper is organized as follows. Section 2 introduces the data and the synoptic situations in the study period. The methods used to estimate turbulent heat fluxes are described in Section 3. The results of the bulk method are described in Section 4, and they are discussed in Section 5. Conclusions are given in Section 6.

\section{Observation}

\subsection{Radiosonde and sea-ice data}

The closed circles in Fig. 2 indicate the upper air sounding stations (Yuzhno-Sakhalinsk, Wakkanai, Shari), other marks over the ocean indicate the points where radiosondes were launched on the icebreaker 'SOYA' during her cruise. Wakkanai and Yuzhno-Sakhalinsk are the operational sounding stations. The Global Positioning System (GPS) sondes were launched at Shari during the period from 26 Jan. to 11 Feb. in 1998, 23 Jan. to 12 Feb. in

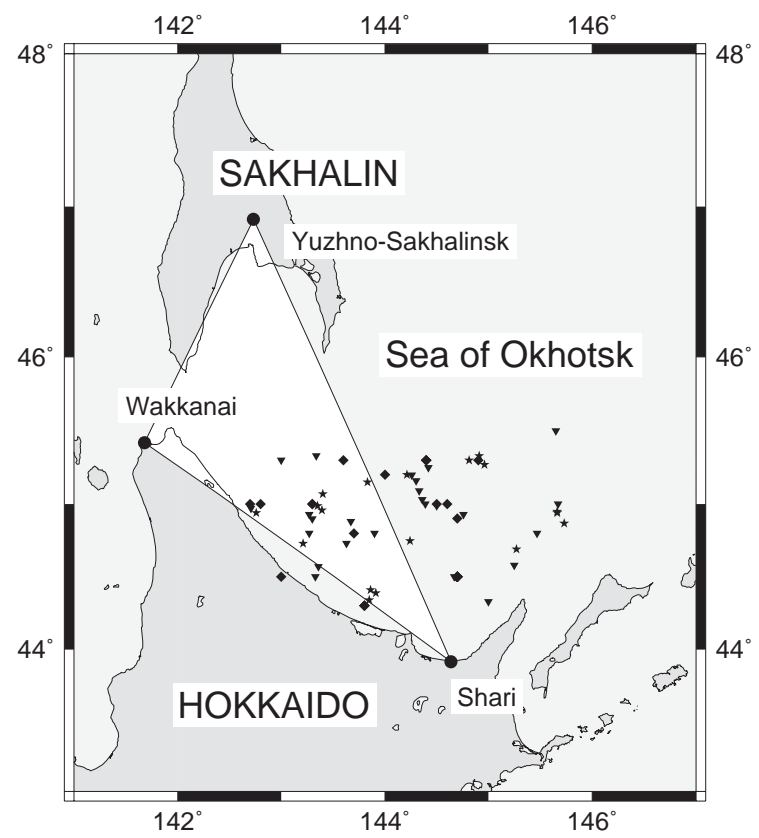

Fig. 2. Locations of aerological stations at land (closed circles) and on the ship ( $\nabla:$ 1998, $\diamond: 1999$ and $\star:$ 2000). The triangle denotes the area where heat budget calculations are made using the upper air soundings at three stations (Shari, Wakkanai and YuzhnoSakhalinsk).

1999 and 11 Jan. to 25 Feb. in 2000. Upper air soundings on the SOYA were made from 4 to 11 Feb. in 1998, from 3 to 10 Feb. in 1999 and from 13 to $17 \mathrm{Feb}$. in 2000. During the cruise, the ice thickness, air temperature, relative humidity, wind, upward and downward shortwave radiation were monitored. The soundings were done every 6 hours $(00,06,12$ and 18 UTC) at Shari, Yuzhno-Sakhalinsk and the SOYA, and every 12 hours at Wakkanai (00 and 12 UTC). 6-hourly data were made of wind, temperature and water vapor mixing ratio by linearly interpolating 12-hourly data at Wakkanai.

The sea-ice data, DMSP-F13 daily sea-ice concentrations in 1998, 1999 and 2000, were obtained from the EOSDIS NSIDC Distributed Active Archive Center (NSIDC DAAC), University of Colorado (published by the National Snow and Ice Data Center 1989). The ice concentration values near the coast were excluded 
1998

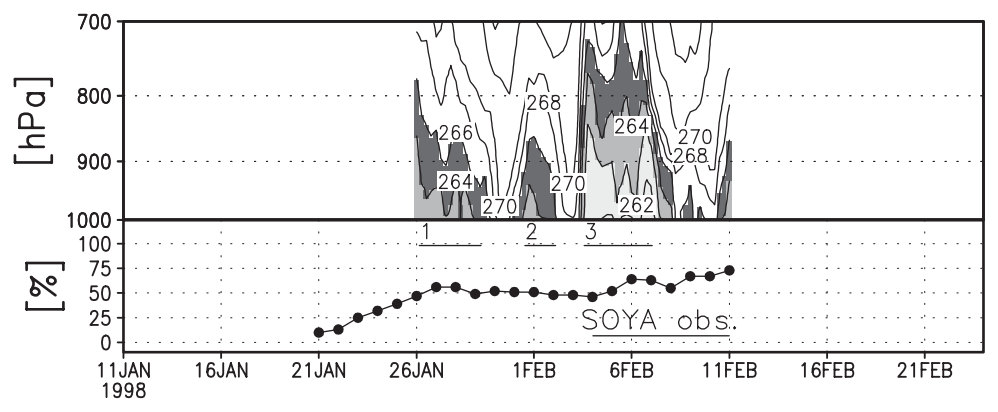

1999
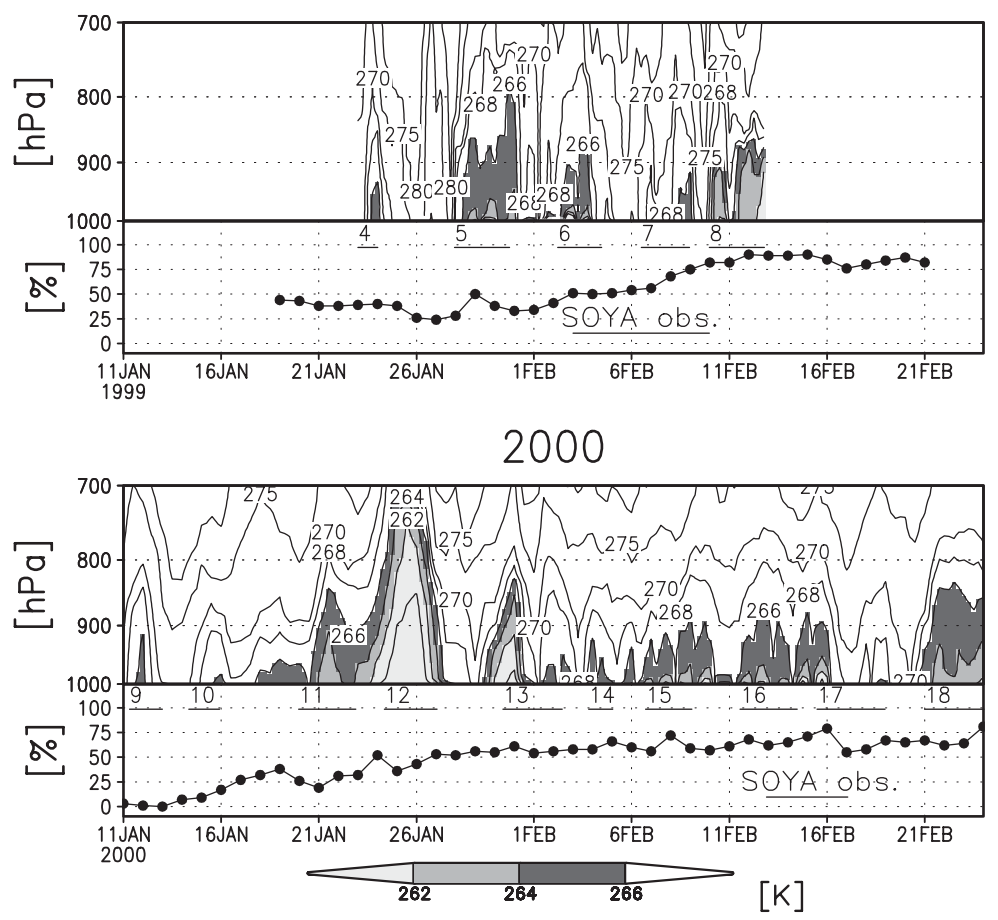

Fig. 3. Time-height cross sections of potential temperature and time series of ice concentration averaged over triangle area shown in Fig. 2 for atmospheric heat budget analysis, respectively. The periods of analysis and maritime observations are indicated by horizontal bars. The number over each bar corresponds to the case number.

when the area-averaged values were calculated in the study.

\subsection{Synoptic situations}

The time-height cross section of the average potential temperature and ice concentration over the analysis area for each year is presented in Fig. 3. The cold-air outbreak events lasting for a few days were often observed within the observation periods for each year. Eighteen cases were selected from the observed cold-air outbreaks for three years (Table 1), considering the onset of cold northwesterly wind at three stations, weather maps, and satellite imageries. Various cases were sampled with respect to the ice concentration, and the temperature of the air mass.

In 1998, the ice concentration rapidly increased before the observation period, so that the ice concentration was almost kept constant in cases- 1 through -2 , then slightly increased after the strong cold-air outbreak event of case- 
Table 1. Date, mixed layer height, observed turbulent heat flux, and ice cover for each case.

\begin{tabular}{|c|c|c|c|c|}
\hline & Case & Mixed Layer Height & Flux & Ice Cover \\
\hline 1 & 00 Z 26 Jan.-12 Z 29 Jan., 1998 & $890 \mathrm{hPa}$ & $48 \mathrm{~W} \mathrm{~m}^{-2}$ & $52 \%$ \\
\hline 2 & 12 Z 31 Jan.-00 Z 02 Feb., 1998 & $925 \mathrm{hPa}$ & $56 \mathrm{~W} \mathrm{~m}^{-2}$ & $50 \%$ \\
\hline 3 & 12 Z 03 Feb.-00 Z 07 Feb., 1998 & $835 \mathrm{hPa}$ & $121 \mathrm{~W} \mathrm{~m}^{-2}$ & $55 \%$ \\
\hline 4 & 00 Z 23 Jan.-00 Z 24 Jan., 1999 & $885 \mathrm{hPa}$ & $85 \mathrm{~W} \mathrm{~m}^{-2}$ & $40 \%$ \\
\hline 5 & 00 Z 28 Jan.-18 Z 30 Jan., 1999 & $780 \mathrm{hPa}$ & $190 \mathrm{~W} \mathrm{~m}^{-2}$ & $39 \%$ \\
\hline 6 & 06 Z 02 Feb.-12 Z 04 Feb., 1999 & $905 \mathrm{hPa}$ & $64 \mathrm{~W} \mathrm{~m}^{-2}$ & $47 \%$ \\
\hline 7 & 12 Z 06 Feb.-00 Z 09 Feb., 1999 & $910 \mathrm{hPa}$ & $55 \mathrm{~W} \mathrm{~m}^{-2}$ & $63 \%$ \\
\hline 8 & 00 Z 10 Feb.-18 Z 12 Feb., 1999 & $955 \mathrm{hPa}$ & $21 \mathrm{~W} \mathrm{~m}^{-2}$ & $85 \%$ \\
\hline 9 & 06 Z 11 Jan.-00 Z 13 Jan., 2000 & $765 \mathrm{hPa}$ & $231 \mathrm{~W} \mathrm{~m}^{-2}$ & $1 \%$ \\
\hline 10 & 12 Z 14 Jan.-00 Z 16 Jan., 2000 & $920 \mathrm{hPa}$ & $46 \mathrm{~W} \mathrm{~m}^{-2}$ & $11 \%$ \\
\hline 11 & 00 Z 21 Jan.-18 Z 22 Jan., 2000 & $855 \mathrm{hPa}$ & $201 \mathrm{~W} \mathrm{~m}^{-2}$ & $25 \%$ \\
\hline 12 & 06 Z 24 Jan.-00 Z 27 Jan., 2000 & $625 \mathrm{hPa}$ & $406 \mathrm{~W} \mathrm{~m}^{-2}$ & $46 \%$ \\
\hline 13 & 12 Z 30 Jan.-12 Z 02 Feb., 2000 & $865 \mathrm{hPa}$ & $110 \mathrm{~W} \mathrm{~m}^{-2}$ & $57 \%$ \\
\hline 14 & 18 Z 03 Feb.-00 Z 05 Feb., 2000 & $895 \mathrm{hPa}$ & $37 \mathrm{~W} \mathrm{~m}^{-2}$ & $61 \%$ \\
\hline 15 & 18 Z 06 Feb.-00 Z 09 Feb., 2000 & $910 \mathrm{hPa}$ & $46 \mathrm{~W} \mathrm{~m}^{-2}$ & $62 \%$ \\
\hline 16 & 12 Z 11 Feb.-12 Z 14 Feb., 2000 & $910 \mathrm{hPa}$ & $22 \mathrm{~W} \mathrm{~m}^{-2}$ & $64 \%$ \\
\hline 17 & 12 Z 15 Feb.-00 Z 19 Feb., 2000 & $915 \mathrm{hPa}$ & $23 \mathrm{~W} \mathrm{~m}^{-2}$ & $66 \%$ \\
\hline 18 & 00 Z 21 Feb.-12 Z 24 Feb., 2000 & $910 \mathrm{hPa}$ & $66 \mathrm{~W} \mathrm{~m}^{-2}$ & $69 \%$ \\
\hline
\end{tabular}

3, which were preliminarily analyzed by Inoue et al. (2001). On the other hand, in 1999, the ice concentration increased in the latter half of the observation period, because strong synoptic lows passed on 26 Jan. and 2 Feb. Although air masses were not so cold through the observation in this year, the cases that had the various ice concentrations were obtained. In the winter of 2000 , the observation period was the longest (about six weeks), and ten cold-air outbreak events were captured. After case-12 (Fig. 1), which is the coldest event for three years, the ice concentration reached around $60 \%$, and was kept almost constant.

\section{Estimation of the turbulent heat flux}

In this work, the turbulent heat fluxes over the ice-covered ocean are estimated using an atmospheric heat budget method from the radiosonde data at three stations. The budget formulation and notations used in this analysis are basically the same as those described in Ninomiya (1975) and Inoue et al. (2001).

The equation of mass continuity, averaged over the analysis area, is expressed as

$$
\overline{\nabla \cdot \mathbf{V}}+\frac{\partial \bar{\omega}}{\partial p}=0,
$$

where $\mathbf{V}(u, v)$ is the horizontal wind vector, $p$ the pressure, and $\bar{\omega}$ the vertical pressure velocity. Here, overbars denote horizontal averages. From this equation, the area mean vertical velocity $\bar{\omega}$ is evaluated as

$$
\bar{\omega} \simeq \int_{p_{\text {toa }}}^{p_{\text {srf }}} \overline{\nabla \cdot \mathbf{V}} d p,
$$

where $p_{\text {srf }}(1000 \mathrm{hPa}$ level $)$ and $p_{\text {toa }}(100 \mathrm{hPa}$ level) denote the bottom and the top of the atmosphere concerned, respectively. In order to reduce the errors in the calculated divergence and the vertical velocity, values were corrected using the method by So (1985). 
The equations of heat and moisture continuity in the $p$-coordinate, averaged over the analysis area, are

$$
\begin{aligned}
& \frac{d \bar{T}}{d t}+\frac{\partial}{\partial p} \overline{\omega^{\prime} T^{\prime}}=Q_{R}+\frac{L}{C_{p}} m, \\
& \frac{d \bar{q}}{d t}+\frac{\partial}{\partial p} \overline{\omega^{\prime} q^{\prime}}=-m,
\end{aligned}
$$

where $Q_{R}$ is the radiative cooling rate, $m$ the net condensation rate, $q$ the mixing ratio of water vapor, $L$ the latent heat release of condensation, $C_{p}$ the specific heat capacity, and $\overline{\omega^{\prime} T^{\prime}}$ and $\overline{\omega^{\prime} q^{\prime}}$ the sub-grid scale eddy transport of heat and moisture, respectively.

The substantial changes of the temperature and moisture due to the synoptic scale motion are evaluated as

$$
\begin{aligned}
& \frac{d \bar{T}}{d t}=\frac{\partial \bar{T}}{\partial t}+\overline{\mathbf{V} \cdot \nabla_{H} T}+\bar{\omega} \frac{\partial \bar{T}}{\partial p}-\frac{R}{C_{p}} \frac{\bar{\omega} \bar{T}}{p}, \\
& \frac{d \bar{q}}{d t}=\frac{\partial \bar{q}}{\partial t}+\overline{\mathbf{V} \cdot \nabla_{H} q}+\bar{\omega} \frac{\partial \bar{q}}{\partial p} .
\end{aligned}
$$

The sum of the sensible and the latent heat fluxes $F S H+F L H$ at the sea or ice surface is evaluated by vertical integration of Eqs. (3) and (4) from the sea surface to the top of the mixed layer as:

$$
\begin{aligned}
F S H+F L H= & -\frac{C_{p}}{g} \int_{p_{t o p}}^{p_{s r f}}\left(Q_{R}-\frac{d \bar{T}}{d t}\right) d p \\
& +\frac{L}{g} \int_{p_{t o p}}^{p_{s r f}}\left(\frac{d \bar{q}}{d t}\right) d p .
\end{aligned}
$$

The top of the mixed layer $p_{t o p}$ is determined as the level at which the diabatic heating rates become zero as in Inoue et al. (2001). To estimate $Q_{R}$, the one-dimensional radiative model Streamer (Key 1999) is used, which is the same method as described by Iwamoto et al. (2001). The Streamer is a radiative transfer model, containing the effects of cloud, realistic incoming solar radiation at the specific location and time, and albedos associated with various surface conditions. We assumed that the cloud appears when the relative humidity exceeds $85 \%$ empirically. The radiative cooling rate from model output as $Q_{R}$ in Eq. (7) was used.

There are some errors in deciding the top of the mixed layer because the atmospheric heat budget method depends on the temporal and spatial averaging schemes. The $p_{t o p}$ at which the heating rate becomes zero is different from that at the SOYA station within $\pm 10 \mathrm{hPa}$, which may come from the errors in the vertical velocity and the vertical advection terms in Eqs. (5) and (6). An error $\Delta p_{\text {top }}$ of $\pm 10 \mathrm{hPa}$ causes an uncertainty of approximately $\pm 10 \%$ in our flux estimation.

Considering that the advance of ice cover in the seasonal ice zone is closely related to the cold-air outbreaks, the averaging period for the estimation of the mean turbulent heat flux should be fit with the time scale of each cold-air outbreak event. Most of the apparent total heat energy source $d\left(\bar{T}+L / C_{p} \cdot \bar{q}\right) / d t$ usually balances the horizontal cold advection $\overline{V \cdot \nabla_{H} T}$ in the boundary layer (e.g., Inoue et al. 2001), suggesting that the role of local time change of air temperature $\partial \bar{T} / \partial t$ is relatively small. In addition to this, the temperature difference between the air and snow/ice surface tends to diminish quickly within a few hours (e.g., Ono 1965), which is much shorter than the duration of a cold-air outbreak event. Therefore, it is expected that cold-air outbreak events lasting a few days are under quasi-steady state.

The turbulent heat fluxes are calculated for eighteen cases. Table 1 shows the results of the estimation of the turbulent heat fluxes. The range of the turbulent heat fluxes is generally large. In the next section, relationships between turbulent heat fluxes, and some parameters (i.e., ice cover, potential temperature, wind velocity) will be investigated.

\section{Heat fluxes over sea surface and ice surface}

Let us assume that the area averaged heat flux is given by

$$
F_{\text {total }}=(1-I C) \times F_{w}+I C \times F_{i},
$$

(Vihma 1995), where $F_{w}, F_{i}$ and $F_{\text {total }}$ are the turbulent heat fluxes over the open water and sea ice, and the sum of them, respectively. $I C$ is the ice concentration $(0 \leq I C \leq 1)$. Here, $F_{w}$ and $F_{i}$ can be written using a classical bulk formula as

$$
\begin{aligned}
& F_{w}=\rho C_{p} C_{H w} U\left(\theta_{w}-\theta\right), \\
& F_{i}=\rho C_{p} C_{H i} U\left(\theta_{i}-\theta\right),
\end{aligned}
$$

where $\rho$ is the air density, $U$ is the wind speed, $\theta$ is potential temperature at $1000 \mathrm{hPa}, \theta_{w}$ and $\theta_{i}$ are the temperature of water surface and ice surface, respectively. $C_{H w}$ and $C_{H i}$ are the bulk 
Table 2. Reference heat transfer coefficient $\left(C_{H w}\right.$ and $\left.C_{H i}\right)$, and surface temperatures $\left(\theta_{w}\right.$ and $\left.\theta_{i}\right)$ derived by a non-linear regression analyses in Eq. (8). The error values are determined by the error in the atmospheric heat budget analysis $\left( \pm 10 \mathrm{~W} \mathrm{~m}^{-2}\right)$. The value in parenthesis denotes the significant level. $r$ and RMS for Eqs. (8) and (12) show the correlation coefficient and root mean square error.

\begin{tabular}{|l||c|c|c|c|c|}
\hline & $C_{H w}$ and $C_{H i}$ & $\theta_{w}$ & $\theta_{i}$ & $r$ & RMS \\
\hline Eq. (8) & $1.33 \pm 0.13(99 \%)$ & $275.6 \mathrm{~K}$ & $262.4 \mathrm{~K}$ & 0.79 & $39.9 \mathrm{~W} \mathrm{~m}^{-2}$ \\
\hline Eq. (12) & - & - & - & 0.82 & $37.3 \mathrm{~W} \mathrm{~m}^{-2}$ \\
\hline
\end{tabular}

heat transfer coefficient for the sensible heat flux over water and ice, respectively. Generally, the values of $C_{H w}$ and $C_{H i}$ in large scale models are fixed and their differences between regions are not usually considered. Therefore, a representative value in the Sea of Okhotsk should be examined and compared with the values in other regions for an application to numerical models.

Using our observational results ${ }^{3}$, we can obtain $C_{H w}, C_{H i}, \theta_{w}$ and $\theta_{i}$ through a multivariate regression analysis. Here, we assumed the Bowen ratio equals one (i.e., $F S H=F L H$ ), by Inoue et al. (2001). We also assumed $C_{H w}=C_{H i}$ in Eq. (8), because thin ice area in leads and polynyas in the Arctic region may be regarded as open water area. As a benefit of this approximation, we could obtain statistically significant regression coefficients at higher than the $99 \%$ level (We could not obtain significant regression coefficients in case of $C_{H w} \neq C_{H i}$ in Eq. (8)). All regression coefficients, and the relationship between the observed heat fluxes and $F_{\text {total }}$ from Eq. (8), are shown in Table 2 and Fig. 4, respectively.

Figure 5 shows $F_{w}$ and $F_{i}$ as a function of the potential temperature and ice concentration at wind velocity of $5 \mathrm{~m} \mathrm{~s}^{-1}$, which is the average wind velocity in our case. The heat flux from the open water is always positive (upward) under cold-air outbreak conditions (Fig. 5-a), while that from the sea-ice surface becomes positive when the temperature is lower than $262.4 \mathrm{~K}\left(=\theta_{i}\right)$. For example, in case-5, the predicted heat fluxes over the open water area and sea-ice area are estimated to be 160 and

3 In this analysis, we excluded the result of case-12 because the deviation from the average is three times larger than the standard deviation $\left(99 \mathrm{~W} \mathrm{~m}^{-2}\right)$. This means that the probability of the occurrence of this case is only $0.27 \%$.

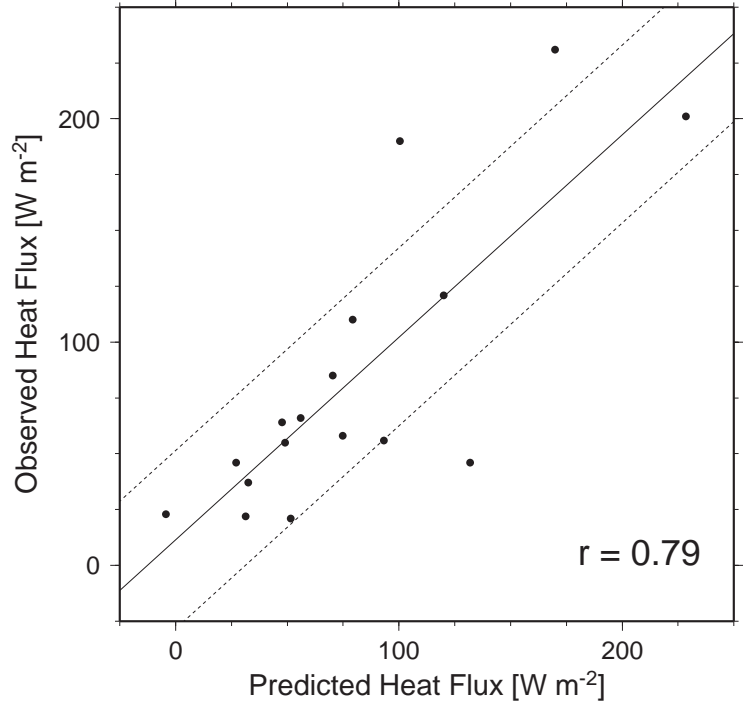

Fig. 4. Scatter plots and regression line between observed and predicted turbulent heat fluxes. Two broken lines denote $\pm R M S$, and a letter $r$ shows the correlation coefficient.

$10 \mathrm{~W} \mathrm{~m}^{-2}$ (total $170 \mathrm{~W} \mathrm{~m}^{-2}$ ), respectively. On the other hand, when the temperature of the atmosphere is higher than $\theta_{i}$, the heat flux over sea-ice area tends to be negative (Fig. 5-b). For example, around $263 \mathrm{~K}$ in the potential temperature and 0.6 in the ice cover (frequent cold-air outbreak conditions), the amount of the heat fluxes from the open sea is about $90 \mathrm{~W} \mathrm{~m}^{-2}$ (Fig. 5-a), while $-10 \mathrm{~W} \mathrm{~m}^{-2}$ is expected over the sea-ice surface (Fig. 5-b). As a result, the expected total heat flux is around $80 \mathrm{~W} \mathrm{~m}^{-2}$.

\section{Discussion}

\subsection{Insulating effect of sea ice on air-sea/ice heat transfer}

In Section 4, it was pointed out that sea-ice surface works as a heat source and sink, de- 

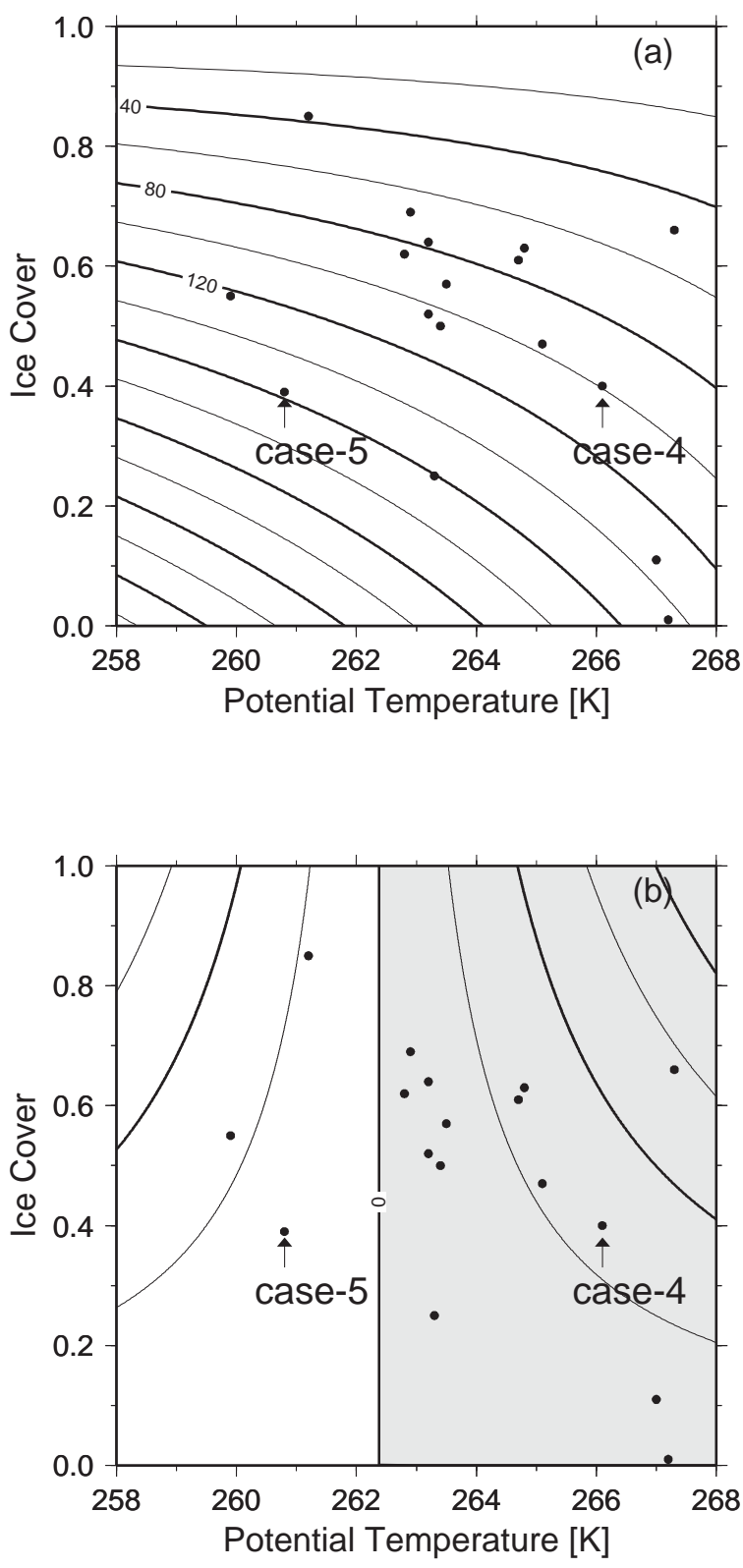

Fig. 5. Contour maps of the turbulent heat fluxes $\left(\mathrm{W} \mathrm{m}^{-2}\right)$, (a) over open water $(1-I C) \times F_{\text {sea }}$ and (b) over sea ice $I C \times F_{\text {ice }}$ as a function of potential temperature and ice concentration at wind velocity of $5 \mathrm{~m} \mathrm{~s}^{-1}$. Shaded area indicates negative values. Estimated turbulent heat flux for each cold-air outbreak case is shown by closed circle. Contour interval is $20 \mathrm{~W} \mathrm{~m}^{-2}$.

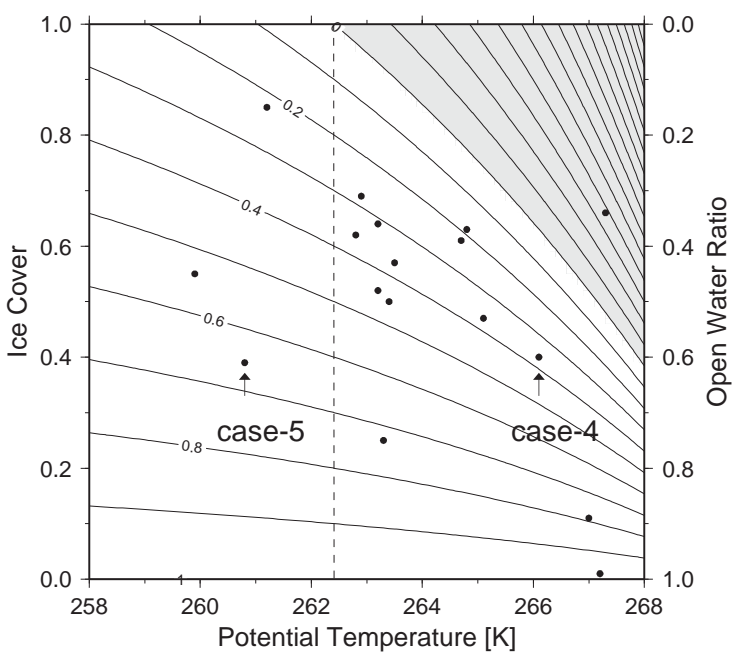

Fig. 6. Contour map of the insulating coefficient $\left(C_{i n s}\right)$ as a function of potential temperature and ice concentration or open water ratio. Shaded area indicates negative value. Insulating coefficient for each case is shown by closed circle. Broken line indicates the reference ice surface temperature.

pending on the temperature difference between the air mass and sea ice. Here, the insulating effect of sea ice on the air-sea heat transfer is examined by using Eqs. (8) and (9), which is evaluated as

$$
C_{\text {ins }}=\frac{F_{\text {total }}}{F_{w}},
$$

where $C_{\text {ins }}$ is defined as the insulating coefficient of sea ice. Figure 6 shows $C_{i n s}$ as a function of the potential temperature and the ice concentration. By definition, $C_{i n s}$ equals to 1.0 for the ice-free condition (open water). Higher ice concentration makes $C_{i n s}$ smaller, suggesting that the insulating effect becomes large. However, $C_{i n s}$ is also sensitive to the temperature under high ice concentration situation. Negative values of $C_{i n s}$ mean that the downward heat flux is dominating in the whole area, including the open sea and sea ice.

When the potential temperature at $1000 \mathrm{hPa}$ is $262.4 \mathrm{~K}\left(=\theta_{i}\right)$, the value of $C_{i n s}$ equals the ratio of open water (see the right axis in Fig. 6 ). Therefore, the coefficient may be interpreted as an 'apparent' open water ratio. Comparing 
the cases- 4 and -5 which have almost the same 'real' open water ratio $(=0.6)$, the apparent open water ratio of the former and latter are 0.38 and 0.65 , respectively. The lower value in case-4, reflects the downward heat flux over sea ice, namely the stronger insulating effect of sea ice. On the other hand, in case-5, the higher apparent open water ratio is brought about by the upward turbulent heat flux through sea ice (Fig. 5-b), suggesting that the ice cover acts as a heating source like open water.

\subsection{Comparisons of the bulk heat transfer coefficient}

In section 4 , a reference value of bulk heat transfer coefficients was obtained $\left(1.33 \times 10^{-3}\right)$ as a secondary product of a regression analysis. Under the assumptions that $F S H=F L H$, $C_{H w}=C_{H i}$, fixed reference temperatures of $\theta_{w}$ and $\theta_{i}$, the estimate for the heat transfer coefficient indicates possible differences in the thermal conditions in the boundary layer and ice conditions between Arctic and marginal/ seasonal ice zones.

In the Arctic region, there are many studies to estimate $C_{H w}$ over leads and polynyas surrounded by thick ice. Generally, $C_{H w}=1.75 \times$ $10^{-3}$ is used in the calculation of the sensible and latent heat fluxes in the Arctic region (e.g., Maykut and Perovich 1987). It is well known that smaller leads and polynyas transfer the sensible heat more efficiently than larger ones by high $C_{H w}$ (e.g., Andreas and Murphy 1986). Maslanik and Key (1995) calculated the sensitivity of $C_{H w}$ to the changes in lead width, wind velocity, air temperature and ice thickness. The value of $C_{H w} \sim 1.7 \times 10^{-3}$ (air temperature $-10^{\circ} \mathrm{C}$, wind velocity $5 \mathrm{~m} \mathrm{~s}^{-1}$ and lead width $\sim 200 \mathrm{~m}$ ) is larger than our result. These higher values reflect the Arctic conditions (e.g., short fetches of leads, and high air-sea temperature difference $20 \sim 40^{\circ} \mathrm{C}$ ).

However, considering lower ice concentration (about $60 \%$ on average) in the Sea of Okhotsk than in the Arctic, we should take into account wider open water area, and relatively lower air-sea temperature difference. Generally, both conditions make $C_{H w}$ and sensible heat flux small (Alam and Curry 1995; Maslanik and Key 1995; Andreas and Cash 1999), because the air mass becomes warmer associated with dominance of the free convection as it flows longer over the open water area. Smith (1988) suggests a value of $C_{H w}=1.35 \times 10^{-3}$ (temperature difference $10^{\circ} \mathrm{C}$ and wind velocity $5 \mathrm{~m} \mathrm{~s}^{-1}$ ), which is representative of open ocean area and agrees with the result $\left(1.33 \times 10^{-3}\right)$.

\subsection{Influence of ice concentration, potential temperature and wind velocity on the turbulent heat flux}

The ice-surface temperature derived in section 4 was a fixed value as a result of the regression analysis. Considering a quasi-steady state, which was used as a basis for the heat budget analysis, the second term of the righthand side of Eq. (8) should be near zero. However, a few amount of heat flux over ice surface was estimated (Fig. 5-b), suggesting that the ice-surface temperature is different between each case or does not still reach at the thermal relaxation state between atmosphere and icesurface. Although the temperature difference between atmosphere and ice-surface is one of the most important factors for the estimation of heat flux in a bulk formula, it is difficult to find out the relative importance for $F_{\text {total }}$ in Eq. (8) among ice concentration, temperature difference and wind velocity. For example, Iwamoto et al. (2001) pointed out the importance of contribution of the ice concentration to $F_{\text {total }}$, while Inoue et al. (2001) emphasized the contribution of the temperature of the air mass.

To evaluate relative importance between three variables (IC, $\theta$ and $U$ ) for the amount of $F_{\text {total }}$, a multivariate regression equation was derived

$$
\begin{aligned}
F_{\text {total }}= & -247.0 I C-14.5 \theta+9.0 U \\
& +3986.0 \quad(R M S=37.3),
\end{aligned}
$$

RMS ( $\mathrm{W} \mathrm{m}^{-2}$ ) means the root mean square error, which shows the standard deviation of the difference between the observed and predicted values by Eq. (12). Each regression coefficient is statistically significant at more than the $99 \%$ level except for the coefficient for wind velocity (more than 85\% level). Although this formula is simpler than Eq. (8), i.e., it does not need reference bulk coefficients and surface temperatures, the obtained coefficient and $R M S$ are slightly better than those from Eq. (8) as shown in Table 2. The standardized regression coefficients between $I C, \theta$ and $U$ are $-0.81,-0.48$ and 0.20 , respectively. From this analysis, the 
primary factor for the amount of the turbulent heat flux is the ice concentration, and second is the potential temperature, which means that the precise treatment of ice concentration is more substantial than that of the ice-surface temperature for the estimation of the flux. The reason for little contribution of the wind velocity may be that each case selected here is chosen not from the various situations, but from cold-air outbreak situations, which may also bring the lower significance of the regression coefficient.

Andreas and Cash (1999) investigated the relationship between the sensible heat flux and the fetch-width of leads and polynyas, and summarized that the mechanical mixing is dominated at the short fetches, while at long fetches the free convection is dominated for the heat transfer. Considering the stronger contribution of potential temperature with wide open water area (small ice concentration), our case can be classified into the free-convective category. Thus, $C_{H w}$ and $C_{H i}$ derived in Section 4, may be useful in case of the free-convective situation during cold-air outbreaks.

\section{Conclusions}

Using radiosonde and ice concentration data, the properties of heat transfer over the icecovered Sea of Okhotsk during cold-air outbreaks were investigated.

From an atmospheric heat budget analysis and a classical bulk method, we found that the turbulent heat fluxes from the open water surrounded by sea ice are always positive (upward), and they mainly contribute to the total heat fluxes. However, the heat flux through ice-surface is positive or negative depending on the air-ice temperature differences. Higher air temperature than that of the ice-surface is often observed in the Sea of Okhotsk, so the heat flux tends to be negative (downward) over sea-ice area.

The insulating coefficient is proposed which evaluates degrees of the insulating effect of sea ice on the heat transfer as a function of the ice concentration and the potential temperature. Although it goes without saying that the higher ice concentration decreases the insulating effect on the upward heat flux, this tendency becomes more prominent as the air temperature in the atmospheric mixed layer is warm, which re- flects that the downward heat fluxes over seaice surface increase in such situations. This fact suggests that the sea ice works as a more effective insulator during weaker cold-air outbreaks.

The reference bulk heat transfer coefficient $\left(1.33 \times 10^{-3}\right)$ in the Sea of Okhotsk was also evaluated and compared with typical values in the Arctic region. Wider open water area (lower ice concentration) and lower air-sea temperature difference bring smaller value in the Sea of Okotsk than those in the Arctic region, reflecting the differences of situations between them. To investigate the relative importance for the amount of total turbulent heat flux among ice concentration, potential temperature and wind velocity, a regression analysis was carried out. The primary contribution to total turbulent heat flux is the ice concentration, second is the potential temperature, and contribution of the wind velocity is rather small.

The relationship obtained in the present analysis reflects limited situations, i.e., coldair outbreaks, which means that it can not be applyed directly to the cases of warm-air advections associated with synoptic-scale disturbances. In addition, the reference sea-ice surface temperature derived in the analysis may be different temporally and spatially in other areas of the Sea of Okhotsk. However, the heat transfer properties in this study (heat transfer coefficients and relative importance of factors for the estimation of heat flux) can be useful for further understanding of the surface heat budget and resultant sea-ice formation during cold-air outbreaks through improvements of the parametarization for numerical models.

\section{Acknowledgments}

The authors express their thanks to all participants in radio sounding and maritime observations on the SOYA and/or at Shari. We also acknowledge Dr. Masayuki Kawashima, Prof. Ehrhard Raschke, Dr. Naoto Iwasaka and Dr. Jinro Ukita for their helpful discussions. This study was supported by a Grant-in-Aid for Scientific Research from the Ministry of Education, Culture, Sports, Science and Technology of Japan, Core Research for Evolutional Science and Technology (CREST) from Japan Science and Technology Corporation (JST) and Research Fellowship of the Japan Society for 
the Promotion of Science for Young Scientists. A major portion of this work is based on a Ph.D. dissertation of J. I. at Hokkaido University.

\section{References}

Alam, Afshan and J.A. Curry, 1995: Determination of surface turbulent fluxes over leads in Arctic sea ice. J. Geophys. Res., 100, 3331-3343.

Andreas, E.L. and B.A. Cash, 1999: Convective heat transfer over wintertime leads and polynyas. $J$. Geophys. Res., 104, 25721-25734.

and B. Murphy, 1986: Bulk transfer coefficients for heat and momentum over leads and polynyas. J. Phys. Oceanogr., 16, 18751883.

Cavalieri, D.J. and C.L. Parkinson, 1987: On the relationship between atmospheric circulation and the fluctuations in the sea ice extents of the Bering and Okhotsk seas. J. Geophys. Res., 92, 7141-7162.

Deardorff, J.W., 1968: Dependence of air-sea transfer coefficients on bulk stability. J. Geophys. Res., 73, 2549-2557.

Honda, M., K. Yamazaki, H. Nakamura and K. Takeuchi, 1999: Dynamic and thermodynamic characteristics of atmospheric response to anomalous sea-ice extent in the Sea of Okhotsk. J. Climate, 12, 3347-3358.

Inoue, J., M. Honda and M. Kawashima, 2001: Air mass transformation processes over the southwestern region of the ice-covered Sea of Okhotsk during cold air outbreaks. J. Meteor. Soc. Japan, 79, 657-670.

Iwamoto, K., K. Domon, M. Honda, Y. Tachibana and K. Takeuchi, 2001: Estimation of surface heat flux based on rawinsonde observation in the southern part of the Sea of Okhotsk under icecovered condition. J. Meteor. Soc. Japan, 79, 687-694.

Key, J.R., 1999: Streamer user's guide. Technical report 96-01, Department of Geography, Boston University.

Maslanik, J.A. and J. Key, 1995: On treatments of fetch and stability sensitivity in large-area estimates of sensible heat flux over sea ice. $J$. Geophys. Res., 100, 4573-4584.

Maykut, G.A. and Perovich D.K., 1987: The role of shortwave in the summer decay of a sea ice cover. J. Geophys. Res., 92, 7032-7044.

National Snow and Ice Data Center, 1989: DMSP SSM/I brightness temperatures and sea ice concentration grids for the polar regions, 1987-. digital data available from nsidc@ kryos.colorado.edu. Technical report, NSIDC Distributed Active Archive Center, University of Colorado at Boulder.

Ninomiya, K., 1975: Large-scale aspects of air-mass transformation over the East China Sea during AMTEX '74. J. Meteor. Soc. Japan, 53, 285303.

Okubo, H. and N. Mannoji, 1994: The influence of the sea ice distribution on the surface wind forecast by Japan Spectral Model. Tenki, 41, 847851 (in Japanese).

Omstedt, A. and D. Chen, 2001: Influence of atmospheric circulation on the maximum ice extent in the Baltic Sea. J. Geophys. Res., 106, 44934500.

Ono, N., 1965: Thermal properties of sea ice. I: Measurements of the thermal conductivity of young winter ice. Low Temp. Sci., Ser., A23, 167-176 (in Japanese with English summary).

Overland, J.E. and C.H. Pease, 1982: Cyclone climatology of the Bering Sea and its relation to sea ice extent. Mon. Wea. Rev., 110, 5-13.

Smith, S.D., 1988: Coefficients for sea surface wind stress, heat flux, and wind profiles as a function of wind speed and temperature. J. Geophys. Res., 93, 15467-15472.

So, S.S., 1985: An observational study of the role of convection in the Baiu situation with special attention to the Arakawa-Schubert cumulus parameterization. Part I: Heat and moisture budgets. J. Meteor. Soc. Japan, 63, 647-655.

Toyota, T., T. Kawamura and M. Wakatsuchi, 2000: Heat budget in the ice cover of the southern Okhotsk Sea derived from in-situ observations. J. Meteor. Soc. Japan, 78, 585-596.

Vihma, T., 1995: Parameterization of surface fluxes over polar region. J. Geophys. Res., 100, 2262522646.

Walsh, J.E. and C.M. Johnson, 1979: Interanual atmospheric variability and associated fluctuations in Arctic sea ice extent. J. Geophys. Res., 84, 915-928. 